\title{
Arquitecturas pantalla en la era de la información. Notas sobre paramentos medliáticos y nuevos paradligmas
}

\author{
Screen architectures in the information age. Notes on media \\ walls and new paradigms
}

\section{Resumen}

*Universidad de Valladolid

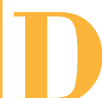

esde mediados del siglo XX se observa un aumento de prácticas arquitectónicas singulares basadas en la incorporación de las tecnologías de la información y la comunicación (TIC) dotando a la arquitectura de pieles y paramentos mediáticos. Este artículo busca sentar las bases de un glosario de ideas, así como una clasificación abierta desde la que poder abordar de manera ordenada el estudio de esta tendencia de vanguardia. Concretamente se analizan dos líneas de investigación. La primera profundiza en los antecedentes de los primeros sistemas mediáticos incorporados al diseño arquitectónico. La segunda muestrea el abanico de ejemplos de arquitecturas mediáticas construidas que mejor han reflejado esta tendencia tecnológica en las últimas décadas. Mediante la revisión bibliográfica, apoyada en una muestra intencional de cien obras seleccionadas y clasificadas, las conclusiones apuntan a una serie de nuevos paradigmas que nos permiten identificar cuándo el entorno arquitectónico responde positivamente al calificativo de mediático y por qué.

Palabras clave: arquitectura mediática; paramento mediático; tecnología; media; nuevos paradigmas.

\section{Abstract:}

Since the mid-20th century, there has been a proliferation of unique architectural practices based on the incorporation of information and communication technologies (ICTs), providing architecture with media skins and facades. This article seeks to lay the foundations for a glossary of ideas, as well as an open classification, to approach the study of this avant-garde trend known as media architecture in an orderly manner. Specifically, two lines of research are analyzed. The first delves into the background of pioneering media systems incorporated into architectural design. The second classifies the range of examples of media architectures that have best reflected this technological trend in recent decades. Through the literature review, supported by a purposive sample of selected works, the conclusions point to a series of new paradigms that allow us to identify when the architectural environment responds positively to the qualifier of mediated and why.

Keywords: media architecture; media facade; technology; media; new paradigms. 


\section{Introducción}

Las tecnologías de la información y la comunicación (TIC) han transformado la sociedad contemporánea. El flujo de información entre el usuario y el medio construido se incrementa y acelera gracias a los avances tecnológicos, desde las comunicaciones wireless, hasta los sistemas de posicionamiento, pasando por la multiplicación de pantallas a todas las escalas, entre otros muchos, que estimulan e impelen nuestros sentidos. En arquitectura, esta tendencia se codifica a través de la denominada arquitectura mediática, la cual incorpora múltiples atributos performativos vinculados a las tecnologías de la información y la comunicación como apuesta explícita.

Durante las dos últimas décadas el interés por la arquitectura mediática se ha visto incrementado y reflejado en congresos científicos, publicaciones y certámenes tecnológico-constructivos que, desde una posición de vanguardia, han abordado esta creciente tendencia detectada en proyectos de arquitectura de todo el mundo. Eventos como Media Architecture (Londres, 2007); Urban Screens Conference (Manchester, 2008); Media Facade Festival (Berlín, 2008); MAB Media Architecture Biennale, celebrados desde 2010 de manera itinerante en Viena, Aarhus, Sídney, Beijing y Ámsterdam -en modo online durante el 2020- con el liderazgo del MAl-Media Architecture Institute de Australia, dan fe de ello.

Dado el incremento de ejemplos y los avances tecnológicos que nutren este campo, se pretende establecer en primer lugar un breve glosario de ideas que nos permita centrar nuestra investigación de manera operativa.

\section{Glosario de ideas}

Inicialmente, cabe distinguir entre arquitectura iluminada y arquitectura mediática. La arquitectura iluminada, tanto con luz diurna como artificial, subraya visualmente partes del edificio mediante la sombra, el color o el brillo de la luz que incide sobre el volumen construido. La diferencia con la arquitectura mediática es clara, por cuanto en la primera lo que se proyecta es luz estática, mientras que en la segunda se proyectan gráficos, texto o imágenes en movimiento, es decir, información (Haeusler, 2009). La diferencia, por tanto, trasciende el paradigma de la arquitectura simplemente iluminada por el más contemporáneo e integral de arquitectura mediática, luminosa, sí, pero donde el edificio deja atrás su papel pasivo, de monumento iluminado, en favor de uno más activo, como cuerpo emisor de luz e información. Por ese mismo razonamiento, el mero hecho de incorporar pantallas de gran escala a la arquitectura no implica que esta se transforme en mediática. Solo lo será si hay en ella un diseño capaz de provocar acciones sensibles, reactivas e interactivas en los usuarios que integre lo espacial y lo mediático (Perrella, 2001)

La arquitectura mediática se conforma de paramentos mediáticos, asociados tradicionalmente a las fachadas, aunque no de forma exclusiva. Para esta investigación, el término media o mediático alude a la comunicación visual en forma de textos, gráficos o imágenes dinámicas. Consecuentemente, la aplicación de dichos atributos a la superficie de un edificio constituye un paramento mediático, también denominado piel mediática. Angelique Trachana (2021) la denomina "envolvente performativa" (p. 173) en un espectro sociológico más amplio. En cualquiera de los casos, esta consta tanto de sistemas tectónicos como de tecnologías de la información. En palabras de M. Hank Haeusler (2009): "mientras que el paramento mediático se puede definir como la inclusión de la comunicación en la fachada, principalmente en forma de medios digitales, la arquitectura mediática describe más bien las implicaciones culturales, sociales y económicas que dichas fachadas suponen para el entorno construido" (p. 14).

Igualmente, conviene referirse al principio de integración como idea rectora en este tipo de diseños. Los paramentos mediáticos, exteriores o interiores, no deben constituir un fin en sí mismo, ni tampoco ser invasivos. Su principal cometido es estar al servicio del proyecto construido y de su entorno. De hecho, paradójicamente, la situación ideal de todo paramento mediático es ser invisible cuando no se encuentre en funcionamiento, sin perjuicio de las funciones constructivas o segregadoras propias a su condición tectónica. Es decir, el paramento debe permitir el paso de la luz natural o la ventilación, si así se le requiere; no debe suponer un coste medioambiental insostenible, o simplemente comportar desventajas constructivas respecto a cualquier otra solución arquitectónica convencional.

Obviamente, el abanico de aspectos técnicos a considerar en el diseño de estas arquitecturas mediáticas trasciende con mucho los márgenes del presente estudio. La condición interior o exterior; el tipo de contenido, su control y su resolución; la relación de aspecto; el comportamiento frente al soleamiento; el ángulo y distancia a los usuarios; el tamaño neto; la estructura; el consumo energético; el tiempo de uso; la vida útil; la facilidad de mantenimiento, o su resistencia al fuego, son solo unos mínimos requerimientos que cabe considerar en este tipo de diseños.

Entre ellos, la resolución constituye un factor crucial que afecta al resto, por cuanto describe en distancias el detalle que tiene el contenido mediático, lo que sin duda condiciona la solución constructiva finalmente adoptada. En un paramento mediático, la resolución se define mediante dos tipos de líneas; unas con contenido, líneas de luz, y otras sin contenido, líneas de oscuridad.

Por tanto, la resolución consta de pares de líneas por unidad de longitud. En este sentido, determinar la resolución necesaria de cualquier paramento mediático requiere determinar la distancia del espectador a la superficie de proyección, cuestión que atañe directamente al espacio arquitectónico. Para hacernos una idea extrapolable, una distancia de 3 metros desde el espectador al plano 
mediático equivale a una distancia de 3 milímetros entre líneas, motivo por el que, a la hora de diseñar una experiencia visual adecuada con espectadores a gran distancia, resultan de utilidad las técnicas de impresión tramada de los cómics de los años 50, ampliamente conocidas por el pop-art de gran formato de Roy Lichtenstein.

Igualmente, la relación de aspecto es otro factor clave, puesto que la arquitectura puede adoptar formas sinuosas que afectan a la percepción del contenido. Por todo ello, forma construida y contenido mediático se deben concebir de la mano, en aras de que ambos se complementen mutuamente.

Finalmente, la determinación del contenido mediático desde el origen del proyecto es otro factor clave en cualquier arquitectura mediática. Este tipo de diseños están condicionados por la necesidad y el tipo de contenido, circunstancia que, lejos de constituir una limitación, en numerosos ejemplos da pie a un alto grado de experimentación arquitectónica que produce los nuevos paradigmas reseñados al final de este estudio.

\section{Metodología}

La metodología que guía esta investigación consta de los siguientes pasos.

En primer lugar, se ha llevado a cabo un análisis de las tecnologías de la información y la comunicación (TIC), especialmente de los sistemas de presentación de contenido mediático. Primero se ha estudiado la evolución histórica de estas tecnologías, cuyo origen podemos situar a finales del siglo XIX con el descubrimiento de las propiedades cromáticas del cristal líquido (LCD) por Friedrich Reinitzer en 1887, y la invención del tubo de rayos catódicos (CRT) por Carl Ferdinand Braun en 1897.

En segundo lugar, se ha realizado una selección preliminar de arquitecturas construidas que, a nuestro juicio, podrían calificarse como mediáticas. El marco temporal discurre de principios del siglo XX hasta nuestros días, en consonancia con la evolución histórica de este tipo de tecnologías. Los ejemplos seleccionados proceden en su mayoría de bibliografía histórica, publicaciones especializadas, premios de arquitectura o bien han sido difundidos por sus autores y/o instituciones promotoras. Respecto a las últimas décadas, en las que el número de ejemplos aumenta considerablemente, cabe destacar las MAB - Media Architecture Biennale como fuente de referencia de gran valor

A continuación, se realiza un análisis tecnológico de dicha selección preliminar, especialmente de los sistemas de proyección de contenido mediático. El análisis se codifica en una serie de esquemas gráficos de síntesis que ayudan a entender e identificar el funcionamiento de cada tipología (Figura 1). Se define así una primera clasificación tipológica de paramentos mediáticos, pues si bien muchas arquitecturas mediáticas comparten objetivos, la mayoría se diferencian entre sí por las tecnologías empleadas en su consecución.

Obviamente, la tentativa metodológica de clasificar este tipo de diseños, sometidos a un alto grado de experimen- tación y a la presión de la carrera tecnológica, no deja de ser contradictoria, por lo que la clasificación propuesta tiene en todo caso un carácter abierto. De hecho, en ese sentido, el presente estudio comparte la estrategia clasificatoria seguida por el MAl-Media Architecture Institute, que desde 2010 ha publicado los Media Architecture Compendium, actualizaciones progresivas de los últimos proyectos de arquitectura mediática con cierto afán clasificatorio. También es reseñable la iniciativa de M. Hank Haeusler, responsable junto a M. Tomitsch y G. Tscherteu de Media Facades - History, Technology, Content (2009); New Media Facades. A Global Survey (2012) y Media Architecture Compendium. Digital Placemaking (2017), publicaciones que también abordan esta cuestión.

A raíz de la citada clasificación tipológica se reevalúa la selección preliminar, concretando finalmente un muestreo de cien obras analizadas según el tipo de paramento mediático, las cuales, ordenadas cronológicamente, muestran la evolución y el auge de esta tendencia. Asimismo, en tanto que el abanico de casos de estudio se acota de manera más precisa, este proceso también define el apartado de los antecedentes, de aquellas obras y autores pioneros de esta tendencia, tales como Herbert Bayer, los Eames, Josef Svoboda y los hermanos Radok.

Los datos obtenidos en esos cuatro pasos metodológicos conforman los siguientes apartados; 4,5 y 6 , que pueden considerarse resultados de la investigación.

\section{Clasificación operativa}

La investigación plantea una clasificación de arquitecturas mediáticas a partir de su funcionamiento técnico. En un primer nivel se distingue entre paramentos mediáticos mecanizados y electrónicos. La diferencia entre ambos radica en la tenencia o carencia de partes móviles. A partir de ese punto, se clasifica la manera en que el contenido se muestra al espectador, diferenciando entre paramentos mecánicos, de proyección, iluminados y de dispositivo tecnológico. Los paramentos mecánicos constan de sistemas cinéticos impulsados por energía eléctrica o hidráulica. Los proyectados recurren a sistemas de proyección de imágenes o datos informáticos mediante proyectores de tipo CRT, DLP, LCD o láser, cual evolución tecnológica del principio de la "linterna mágica" (Vermeir, 2005, p. 128). Los iluminados utilizan fuentes de luz de incandescencia, fluorescencia o diodos emisores de luz LED dispuestas en tramas de pixels que permiten emitir patrones de información lumínica controlada digitalmente. Y en último lugar, los paramentos de dispositivo tecnológico se aprovechan de sistemas integrales prediseñados para la visualización de imágenes.

A su vez, tres de los grupos mencionados admiten categorizaciones particulares dependiendo de la tecnología de la fuente de luz utilizada. Por ejemplo, los paramentos proyectados pueden ser de proyección frontal o retroproyección. Los iluminados, pueden emplear luz artificial o ventanas rasterizadas. Y finalmente, los de dispositivo tecnológico pueden emplear componentes electrónicos planos de tipo pantalla, o unidades voxel de carácter tridimensional. 
En resumen, encontraríamos siete métodos de disposición de contenido $y$, por ende, siete tipos básicos de paramentos mediáticos: mecánicos $(A)$; proyectados $(B)$; retroproyectados (C); iluminados $(D)$; rasterizados $(E)$; pantallas $(F)$ y voxel $(G)$, caracterizados por la tecnología de presentación de contenido, la cual condiciona el diseño arquitectónico, el punto de vista del espectador y la fuente de luz empleada (Figura 1). A su vez, estos siete tipos de paramentos mediáticos se pueden combinar con multitud de sistemas tectónicos, lo que da lugar a un amplio abanico de soluciones constructivas de vanguardia que ponen en evidencia la oportunidad del presente análisis.

Tal como apuntábamos al comienzo de este apartado, el interés por la arquitectura mediática se ha visto incrementado en las últimas décadas; sin embargo, cabe subrayar que no se trata de un fenómeno exclusivamente contemporáneo. De hecho, desde mediados del siglo XX la experimentación en campos como el diseño de exposiciones ha facilitado la incorporación de aspectos perceptivos propios de los media a la génesis del proyecto arquitectónico.

\section{Precursores en tiempos de experimentación}

Herbert Bayer anticipa en Fundamentals of Exhibition Design (1939) la potente conexión entre el espacio construido y el contenido visual mediático que este puede acoger: "Las mayores posibilidades del diseño de exposiciones descansan en la aplicación universal de todos los medios conocidos de diseño: el diagrama, las letras, la palabra, la fotografía, la arquitectura, la pintura, la escultura, el tono, la luz, el cine" (Bayer, 1939, p. 17). Sus palabras son el fruto condensado de las experiencias vividas al amparo de la Bauhaus hasta 1928. Para él, el espacio expositivo semeja un paisaje audiovisual, donde el intercambio de información se produce de forma simultánea, en todo el campo de visión y a través de diversos medios.

Bayer había puesto en práctica esta idea en la Sección Alemana del Salón Anual de la Société des Artistes Décorateurs de París de 1930 junto a Walter Gropius, Marcel

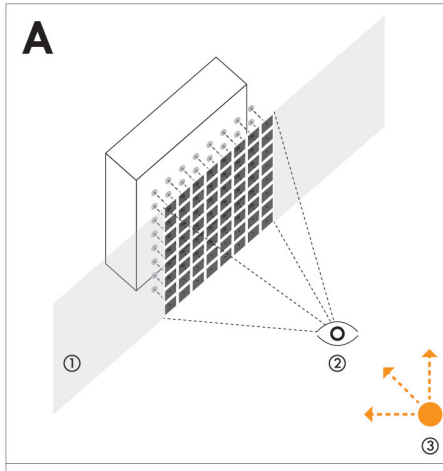

D

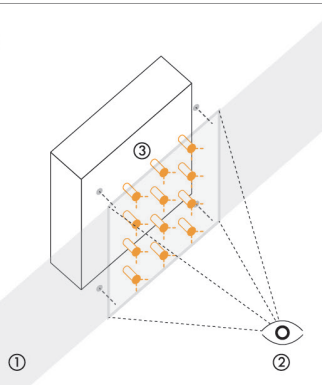

G $\stackrel{2}{2}$ E

Tipologías de paramentos mediáticos

A - Mecánicos

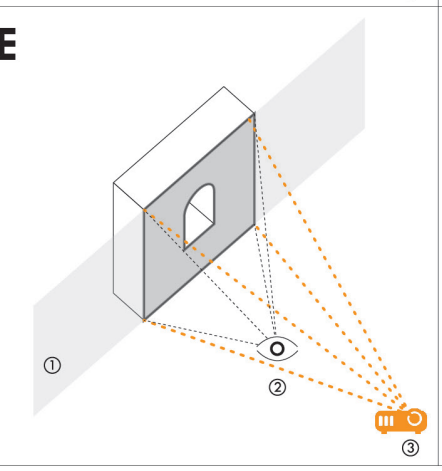

C

B

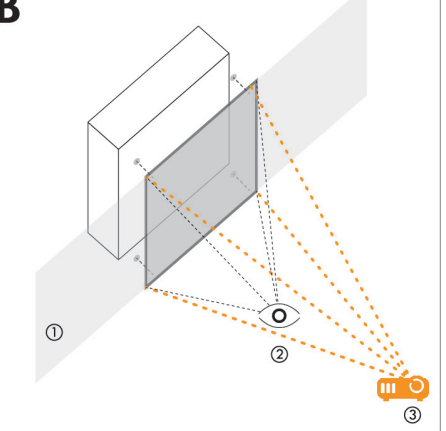

$\mathbf{F}$
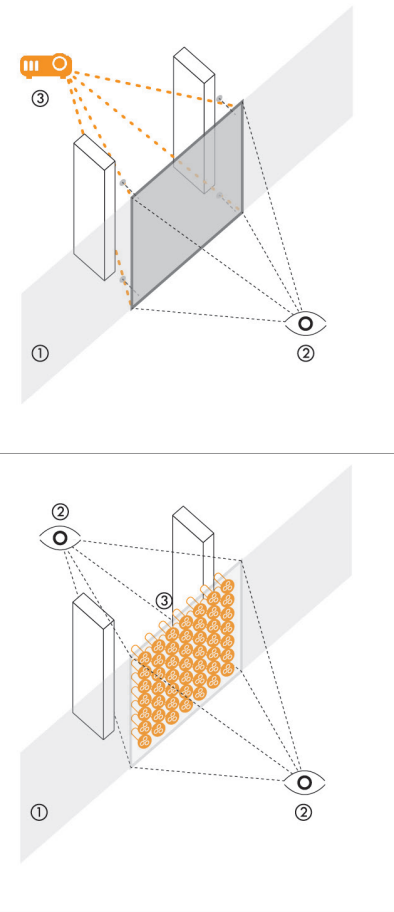

B - Proyectados

C - Retroproyectados

D - lluminados

E - Rasterizados

F - Pantallas

G - Voxel

Leyenda numérica

1- Plano de contenido mediático

2- Punto de vista del espectador

(1)

3- Fuente de luz / contenido mediático

Figura 1: Tipologías básicas de paramentos mediáticos en arquitectura

Fuente: Elaboración propia 
Breuer y László Moholy-Nagy (Bayer y Gropius, 1930; Miller, 2017). Su propuesta trascendía la mera disposición de objetos de diseño moderno para ofrecer toda una ex periencia visual hilvanada por la percepción del visitante, por la imagen y las impresiones hápticas (Brüning, 1982; Brüning, 1995; Jaeggi, 2007). Tanto es así, que para dicho evento diseña una suerte de muro-panóptico de estímulos visuales inclinados y orientados hacia el espectador Wilhelm Lotz da testimonio fotográfico de ello en el número 5(11/12) de Die Form de 1930, la revista oficial de Werkbund, donde explica que el objetivo era mostrar los diseños modernos en la órbita de la Bauhaus, haciendo converger lo industrial, lo gráfico, lo comunicativo y lo arquitectónico (Lotz, 1930). Bayer lo sintetiza en la Section Allemande Catalogue mediante un fotomontaje donde los planos flotantes cargados de información visual, mediáticos, se liberan de la ortogonalidad de los paramen- tos dando lugar a una estancia dentro de otra, hecha de estímulos visuales (Figura 2). En el centro se yergue un espectador con cabeza en forma de ojo surrealista, de cuya mirada emergen líneas de visión que justifican la composición del espacio construido por dichos paneles mediáticos (Bayer y Gropius, 1930). Ellen Lupton (2020) se refiere a este ideograma como el "hombre ojo" (p. 82), si bien para nosotros resulta más apropiado hablar de la mirada inclusiva, en coherencia con el título que le otorga el propio Bayer en Fundamentals of Exhibition Design: "inclusive picture of all possibilities" (Bayer, 1939, p. 25). Así la unificación de diseño expositivo y tecnología mediática pone el foco en la mirada del usuario como nuevo paradigma en la concepción del espacio construido (Jaeggi, 2007).
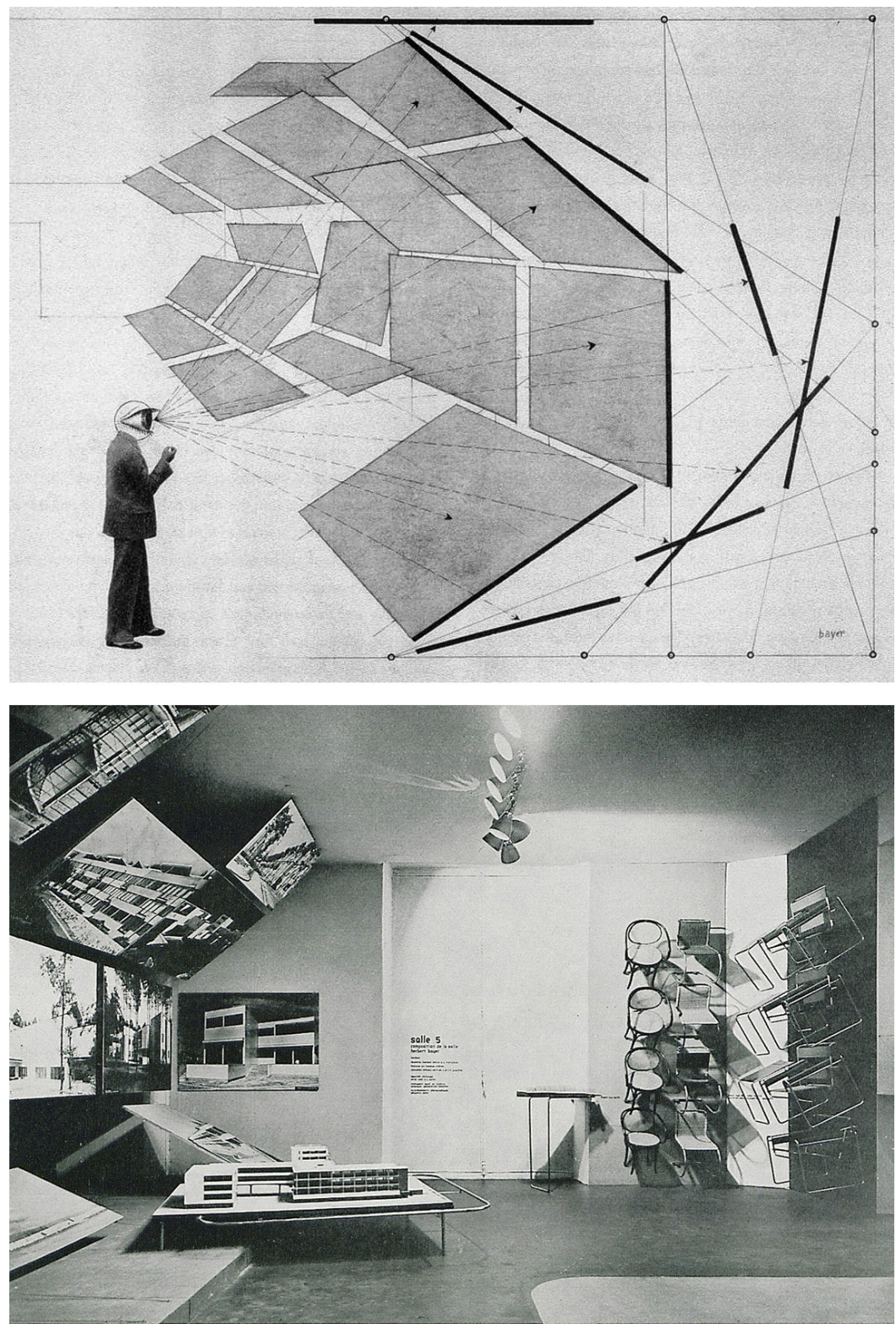

Figura 2: Herbert Bayer. Sección Alemana. Salón Anual de la Société des Artistes Décorateurs, París, 1930 Fuentes: Bayer, H. y Gropius, W. (1930). Section Allemande Catalogue. Berlin: Verlag Hermann, Reckendorf / Lotz, W. 
Las investigaciones de Herbert Bayer resultan por ende precursoras inconscientes de la arquitectura mediática por subrayar la componente espacial que reside en los medios visuales incorporados a la arquitectura. Tal y como describe Bayer, las nuevas posibilidades del diseño de exposiciones pasan por estimular al usuario en todo su "campo visual" (Bayer, 1939, p. 17). La combinación intencionada de arquitectura y media impele el movimiento a través del espacio construido, sumergiendo a los usuarios en la imaginería: "el tema [o contenido] no debe mantener distancia respecto del espectador, debe acercarse a él, penetrar y dejar una impresión en él, debe explicar, demostrar, e incluso persuadir y llevarle a una reacción planificada y directa" (Bayer, 1939, p. 17). En ese sentido, no es de extrañar que Bayer afirme que e diseño expositivo se sirve en gran medida de la "psicología del diseño publicitario" (Bayer, 1939, p. 17), porque provoca la acción a través de estímulos audiovisuales. Como él mismo reseña, perseguía ampliar "el campo de visión y utilizar otras superficies aparte de la vertical, añadiendo nuevos focos de interés", es decir, "cambiar la forma en que el visitante percibe la exposición" (Bayer, 1967, p. 32). En cierta medida, Bayer se adelanta al citado principio de integración de la arquitectura mediática, pues insiste en la capacidad del contenido visual para construir el espacio, y no así en las estructuras o paneles que lo soportan (Bayer, 1967). Observando con detalle la publicación de Wilhelm Lotz sobre la instalación de la Sección Alemana, se observa que las fotografías se presentan suspendidas en el aire sin marcos ni anclajes visibles: un buen ejemplo de las prioridades de Bayer, en cierta medida anticipatorias del despliegue mediático contemporáneo.

Tal y como demuestra Herbert Bayer, la tendencia hacia lo performativo, lo dinámico, lo cambiante y lo múltiple no es una apuesta exclusiva del siglo XXI. De hecho, poco después de publicar Fundamentals of Exhibition Design diversas Exposiciones Universales de los años 50 y 60 acogieron trabajos de Josef Svoboda, Alfred y Emil Radok, y los Eames, en los que la simultaneidad y la proyección de imágenes dinámicas se convierten en el leitmotiv del espacio arquitectónico (Nieto, 2016).

La Exposición Universal de Bruselas (1958) acogió en el Pabellón de Checoslovaquia de Frantisek Cubr, Josef Hrubs y Zdene Pokorny dos instalaciones audiovisuales a cargo de Svoboda y los hermanos Radok tituladas Polyekran y Laterna Magika (Ursini, 2009). Polyekran constaba de ocho proyectores de diapositivas fijas y siete de película, sincronizados al ritmo de la música, que mostraban imágenes de Praga en ocho pantallas suspendidas en ángulo sobre un fondo negro. La proyección múltiple se basaba en el principio abstracto del collage, donde los objetos y superficies se relacionan conformando una nueva realidad de significados uniformes en su heterogeneidad (Burian, 1971). Laterna Magika resultaba aún más elocuente pues hibridaba actores reales con imágenes proyectadas. Se trataba de un espacio escénico conformado por ocho pantallas móviles. Las imágenes en movimiento interactuaban con la acción dramática de los actores, estableciendo una relación entre cuerpo e imagen que superponía tiempos y realidades. En ocasiones parecía que los actores salían de la pantalla para hacerse corpóreos sobre la escena, y viceversa, trascendiendo con ello no solo los límites entre teatro y cine, sino también la frontera ilusoria entre lo real y lo virtual (Ursini, 2009; Nieto, 2016)

Svoboda volvió a poner en práctica la técnica de Laterna Magika al año siguiente en Their Day para la Feria Internacional de Moscú (1959), evento en el que los Eames, conocedores de la obra del checo, presentan Glympses of U.S.A. (Ostroff, 2015). Se trataba de una producción audiovisual múltiple proyectada sobre siete pantallas suspendidas de la cúpula geodésica diseñada por Buckminster Fuller (Figura 3). Las pantallas ofrecían una experiencia sensorial envolvente dispuestas sobre los espectadores siguiendo una ligera curvatura. Como reseña Beatriz Colomina, no se trataba únicamente de imágenes colgadas de una cúpula, sino de pantallas que definían un espacio dentro del espacio, donde las proyecciones rompían la perspectiva tradicional al no privilegiar ningún punto de vista y la totalidad solo podía ser aprehendida a través del movimiento por el pabellón (Colomina, 2001).
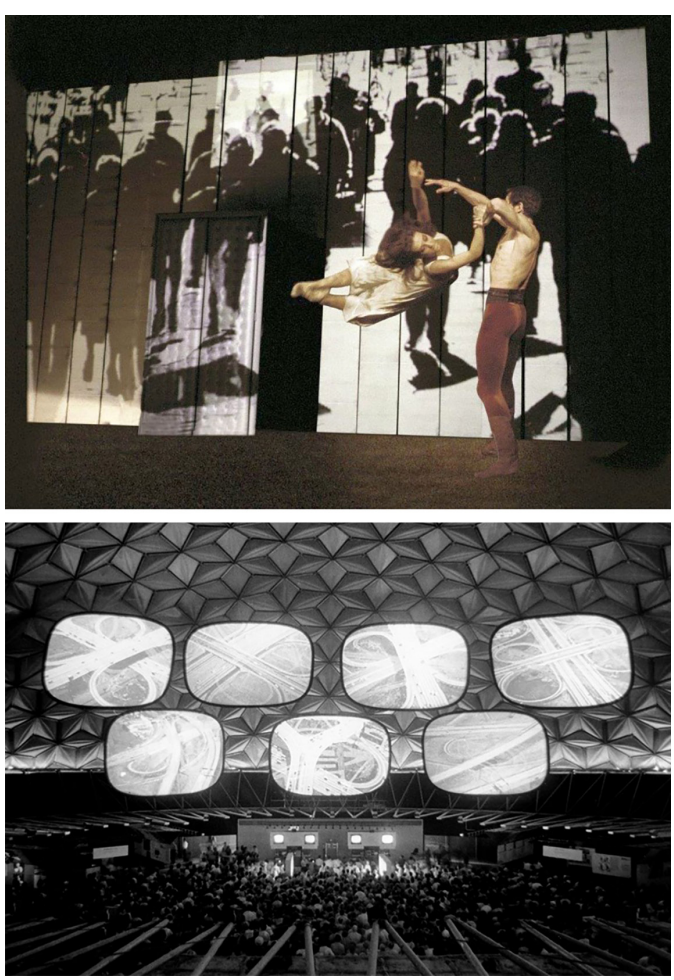

Figura 3: Josef Svoboda y Emil Radok. Laterna magika. Bruselas. Expo 58 (arriba) y Charles y Ray Eames. Glimpses of the USA. Moscú, 1959 (abajo)

Fuentes: http://www.svoboda-scenograph.cz/en/ laterna-magika/. Imagen de dominio público / Albrecht, D. (1997) The Work of Charles and Ray Eames: A Legacy of Invention. New York: Harry N. Abrams, Inc., 32

Las experiencias combinadas de ambos equipos se sucedieron de forma brillante. Para la Exposición Universal de Nueva York (1964) los Eames idearon con Eero Saarinen el Ovoid Theatre de la empresa IBM (Ostroff, 2015). En este caso, además de acometer el diseño del sistema multipantalla para la película Think (Neuhart, 1989) también proyectaron el edificio, un volumen ovoide con acceso mecanizado mediante un graderío móvil ascendente. En su interior, el espectador circulaba transportado en 
un ballet mecánico que solo requería dejarse invadir por las imágenes que iban apareciendo en las pantallas. Así, arquitectura y medios visuales formaban una unidad conceptual, parte de una misma idea donde la mirada, no as el cuerpo, era el agente activo del desarrollo dramático.

Svoboda recogió el testigo en la Exposición Universa de Montreal (1967) presentando un conjunto de cuatro instalaciones audiovisuales unificadas bajo el título Polyvision: The State of Textile, Pressure Vessel, Symphony y The Birth of the World, todas caracterizadas por aunar teatro e imagen en movimiento. Las dos primeras eran una variante de Polyekran; sin embargo, las dos últimas sí introducían novedades de interés para nuestra investigación. Por un lado, Symphony consistía en una proyección cinematográfica y de diapositivas sobre volúmenes; cubos, prismas y esferas, que se movían vertical y horizontalmente (Bablet, 1970). La escena habitada por dichos cuerpos geométricos constituía una composición plástico-cinética anticipatoria de los actuales paramentos mecánicos (A) o rasterizados (E). Por otro lado, The Birth of the World era una proyección de imágenes sobre una pared-mosaico denominada Diapolyekran, compuesta por ciento doce teselas móviles que se acercaban y alejaban del espectador provocando un collage cinético que alternaba entre lo bidimensional y lo tridimensional. Salvando las distancias, una experiencia que cabe asimilar a los actuales paramentos voxel $(G)$ por su componente tridimensional.

Las experiencias de Bayer, Svoboda y los Eames se vieron impulsadas por el desarrollo de los media y el deseo de incorporar la imagen en movimiento al diseño del espacio arquitectónico. El auge del cine desde principios de siglo XX, unido a la democratización paulatina de la televisión a partir de los años 50, dieron alas a una nueva fenomenología que surge de rodear al espectador de imágenes dinámicas (Colomina, 2001). No obstante, la tecnología de proyección de contenido condicionó el camino iniciado por dichos pioneros, sobre todo, a la hora de proyectar imágenes en el exterior de manera eficaz, sin duda, el gran reto técnico de la arquitectura mediática. De hecho, aún faltaba casi una década para que viera la luz el primer prototipo de pantalla de diodos emisores de luz LED, desarrollado por James P. Mitchell en 1977 y presentado en la Exposición de Ingeniería de Anaheim de mayo de 1978 .

\section{Arquitecturas pantalla en la era de la información}

A la luz de los antecedentes y los tipos básicos de paramentos mediáticos expuestos con anterioridad, la investigación acota el muestreo preliminar de obras que encajan en la definición aportada de arquitectura mediática. Para ello se establece como punto de partida uno de los primeros ejemplos que introducen de manera explícita un paramento mediático tras las experiencias mencionadas de Bayer, Svoboda y los Eames: se trata de proyecto ganador del concurso del Centro Georges Pompidou (1971). A partir de esa fecha, el estudio clasifica cien ejemplos de arquitecturas mediáticas distribuidas por todo el mundo que Ilegan hasta el año 2016, cuyos paramentos encajan en los citados tipos: mecánicos $(A)$ proyectados (B); retroproyectados (C); iluminados (D); rasterizados (E); pantallas (F) y voxel (G) (Figura 4).

La clasificación propuesta se hace eco de las tecnologías de proyección de imágenes, las cuales se incorporan en la génesis de los respectivos diseños bien de manera parcial, o incluso como argumento arquitectónico identitario. El gráfico resultante revela cómo el número de arquitecturas mediáticas aumentan de manera exponencial desde finales del siglo XX, disparándose entre 2006 y 2008, periodo que coincide con la abundancia de eventos: Media Architecture (2007); Urban Screens Conference (2008); Media Facade Festival (2008); MAB - Media Architecture Biennale (2010-2020). Obviamente, el interés provocado por dichos eventos pone el foco en la arquitectura mediática, pero esta a su vez retroalimenta la celebración de estos. Por otro lado, el análisis demuestra cómo la producción de arquitecturas mediáticas está íntimamente ligada a las mejoras en la tecnología que las propicia. En ese sentido, no resulta extraño observar cómo los paramentos mediáticos de tipo iluminados (D) y de pantallas $(F)$, aquellos que emplean tecnología de diodos emisores de luz LED, la más eficiente económica y energéticamente, constituyen un $80 \%$ del total clasificado (Figura 5).

Si bien no es el objetivo de este artículo pormenorizar detalladamente cada ejemplo clasificado, de entre ellos algunos sí resultan de especial interés por representar tendencias extrapolables al resto.

El primero es el Centro Georges Pompidou (1971). Destaca por su carácter pionero que responde al requerimiento de un diseño que pudiera evolucionar de manera constante. La propuesta ganadora de Renzo Piano, Richard Rogers y Gianfranco Franchini planteaba la conocida megaestructura claramente influida por las ideas de Archigram y los Metabolistas japoneses; una máquina transparente, abierta y estructurada que ofrecía la máxima flexibilidad. El edificio es ampliamente conocido porque las instalaciones y sistemas de comunicación quedan vistos al exterior; si bien, en la fase de concurso se incorporaba también una pantalla gigante, técnicamente no especificada, para proyectar mensajes electrónicos hacia la Plaza Georges Pompidou (Marinelli, 1978) (Figura 6). Esta fachada mediática no se desarrolló durante el proyecto, posiblemente por motivos técnicos y económicos (Piano et al., 1987). No obstante, pese a dicha renuncia, la comunicación es el verdadero tema del edificio, metafóricamente representada por la paleta de colores que identifica sus sistemas técnicos; blanco - estructura; azul- sistemas de aire; verde- sistemas de agua; amarillo - sistemas eléctricos; rojo- circulaciones y seguridad. De hecho, la génesis del Centro Pompidou plantea el desplazamiento del espacio arquitectónico hacia el espacio de la comunicación orientada a su entorno próximo (Puglisi, 1999). Gracias a la piel de vidrio, la imagen de sus componentes se presenta como vistos por rayos-x, y aún sin la citada pantalla urbana, la combinación de códigos gráficos convierte el edificio en un código semiótico de gran escala, que actúa como fuente de luz e información, subrayando ya en los años 70 las potencialidades de la arquitectura mediática para estimular al espectador y hacerle partícipe del entorno construido. 


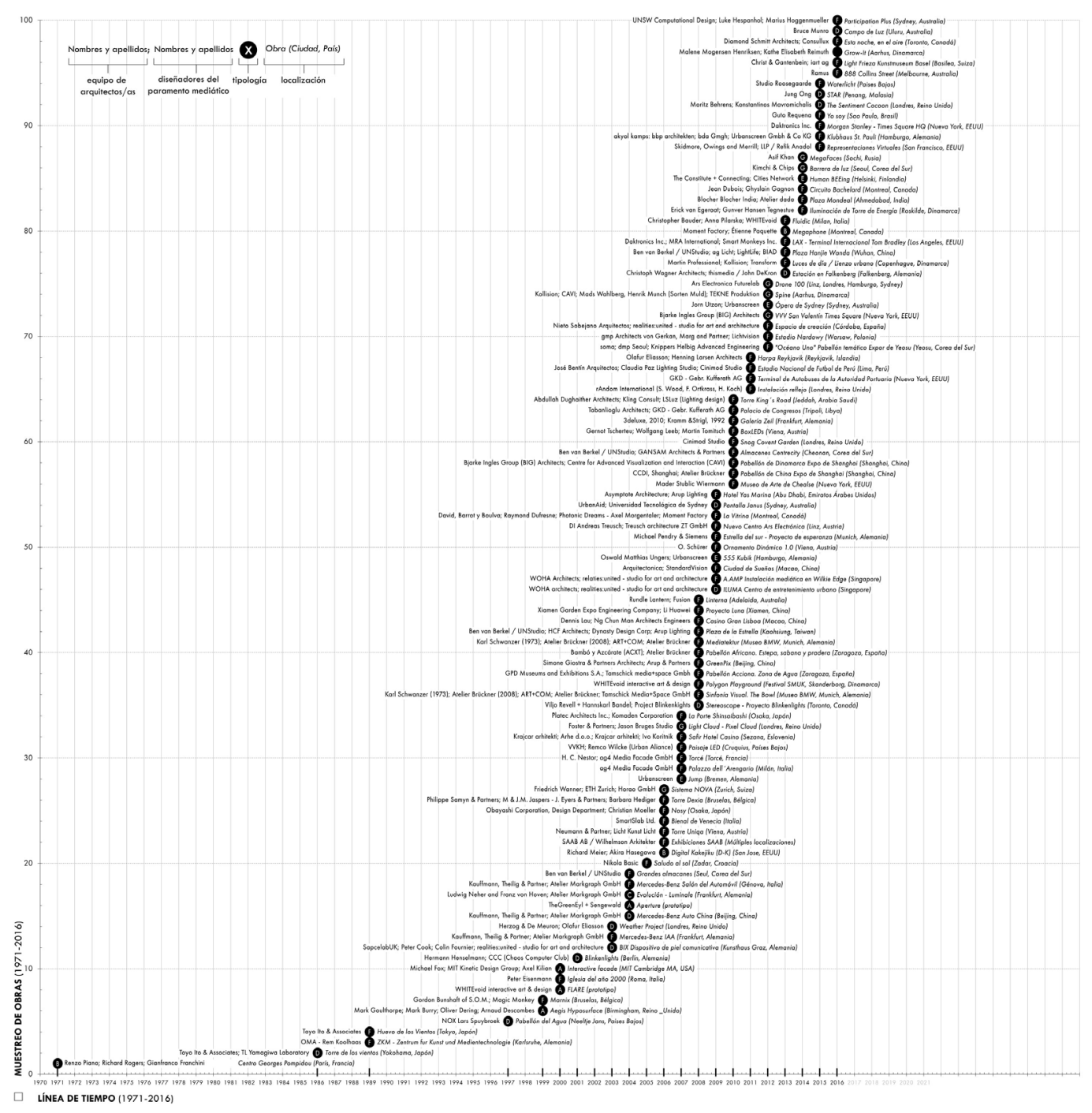

Figura 4: Muestreo de arquitecturas mediáticas clasificadas por tipos básicos de paramentos 1971-2016 Fuente: Elaboración propia

La propuesta de Toyo Ito para la Torre de los Vientos (1986) retomó el testigo casi una década después. Bajo el pretexto de camuflar una chimenea de ventilación de la estación de tren de Yokohama, Ito proyecta una torre de espejos de 21 metros de altura rodeada por una estructura metálica de base elíptica revestida de placas acrílicas reflectantes. En palabras del arquitecto japonés, "la intención era escoger la corriente de aire y el sonido del ambiente en el que está emplazado el proyecto y transformarlas en signos luminosos, es decir, informaciones visuales" (Ito, 2000, p. 146). Así, el edificio perdería su presencia como objeto físico tras la puesta de sol y se transformaría en un fenómeno de luz emitida a entorno, en información visual codificada por la instalación arquitectónica (Roulet y Soulié, 1991). Para lograrlo se instalaron tres grupos lumínicos; 1280 mini-lámparas puntuales; 12 anillos lineales de neón en la superficie vertical de la torre; y 30 focos de dispersión en el terreno, 26 de ellos en el perímetro interior del volumen (Ito y Maffei, 2001). El resultado es que durante el día la torre se presenta como un cuerpo opaco, pero al caer la noche se desvanece convertida en un gran dispositivo emisor de luz e información (Figura 7). La iluminación concebida por Toyo Ito en colaboración con TL Yamagiwa Laboratory responde a parámetros ambientales como los niveles de ruido o viento, cambiando en intensidad, dirección y tipo. Por ejemplo: los anillos de neón marcan las horas; los reflectores de suelo se atenúan con el viento y las mini-lámparas interpretan diferentes flujos dependiendo del ruido ambiental. Se trata del ejemplo construido que mejor condensa los sistemas retroproyectados (C) e iluminados (D), representando uno de los proyectos más tempranos de interacción digital entre arquitectura y entorno, capaz de hacer "visible el ruido (y el aire) existente en la ciudad" (Ito, 2000, p. 124).

Toyo Ito también llevó a cabo el Huevo de los Vientos (1990-91) en Tokio, un homenaje velado al citado Ovoid Theatre de los Eames y Saarinen. El diseño consta de un elipsoide suspendido donde se retroproyectan imágenes digitales sobre planchas de aluminio perforado. El valor de estas dos instalaciones de Toyo Ito es que vieron la luz, pues el número de arquitecturas mediáticas ideadas y no construidas a finales del siglo XX es considerable. 

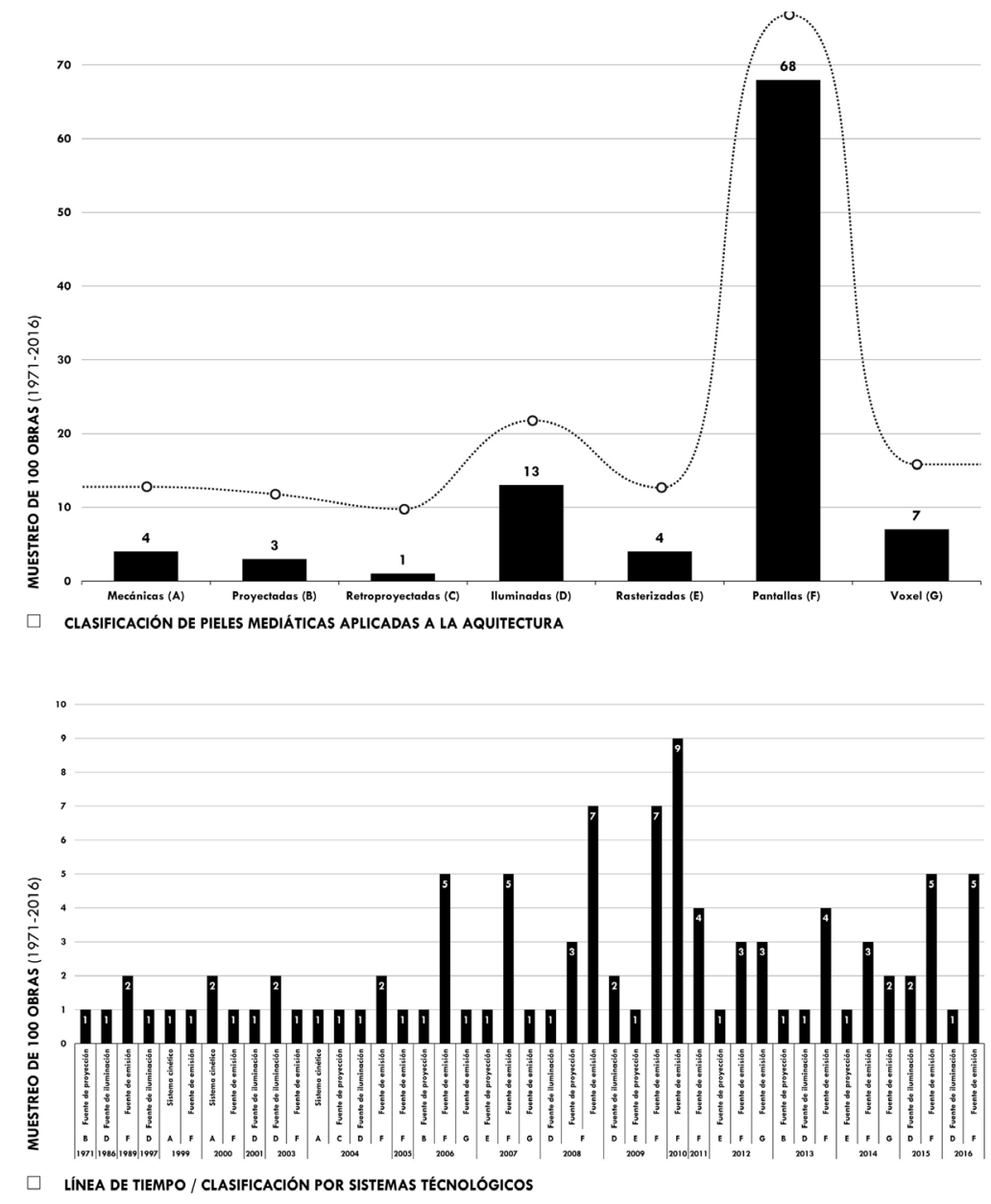

Figura 5: Muestreo de arquitecturas mediáticas clasificadas por tipos básicos de paramentos Fuente: Elaboración propia

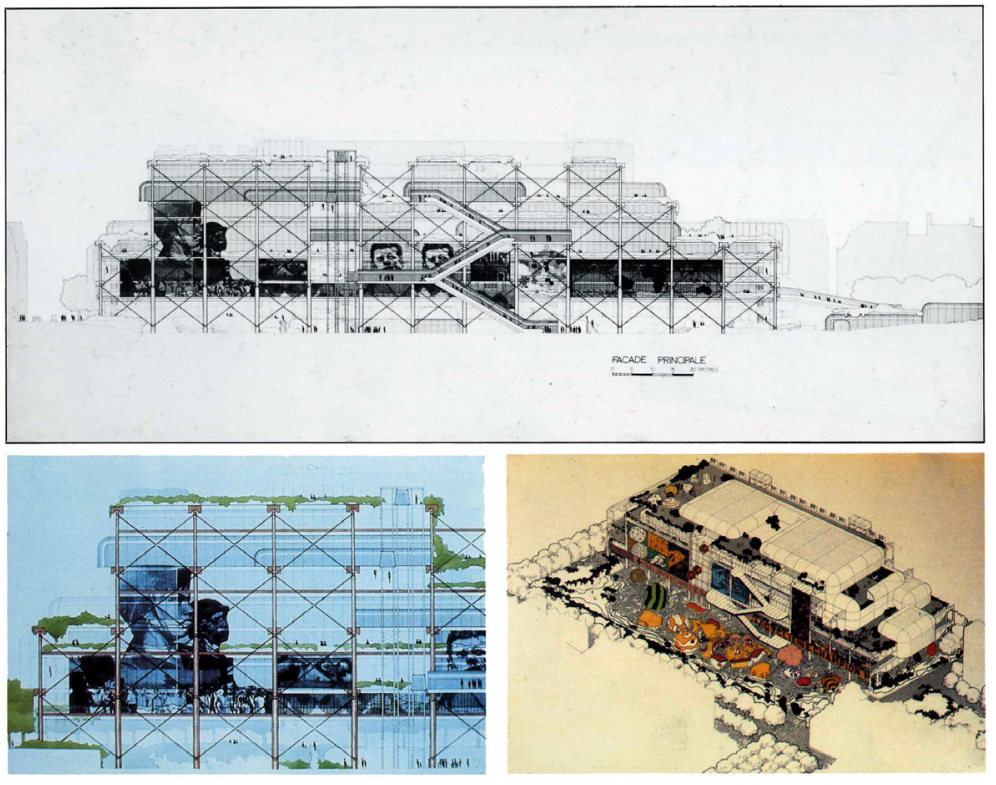

Figura 6: Renzo Piano, Richard Rogers y Gianfranco Franchini. Fachada mediática del concurso al Centro Georges Pompidou. París, 1971 
Solo por poner dos ejemplos, el Zentrum fur Kunst und Medientechnologie (1989) de OMA-Rem Koolhaas para Karlsruhe; o la Iglesia del año 2000 en Roma, diseñada por Peter Eisenmann con fachadas de cristal líquido LCD: "una forma contemporánea de vidriera", en palabras del propio autor (Eisenmann, 1997, p. 156).

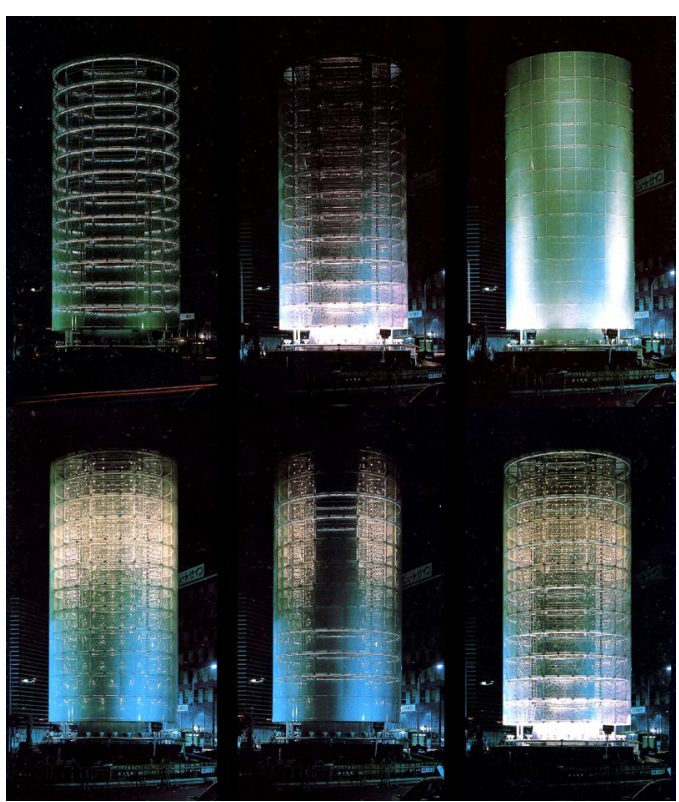

Figura 7: Toyo Ito. Torre de los Vientos. Yokohama, 1986 Fuente: Roulet, S. y Soulié, S. (1991). Toyo Ito l'architecture de l'éphémère. Moniteur, 118

A principios del siglo XXI, encontramos otro caso de gran interés, el Kunsthaus Graz (2003) de Peter Cook y Colin Fournier, que nos recuerda a las citadas utopías de Archigram. El edificio construido a orillas del río Mur a su paso por Graz integra tecnología mediática y superficies arquitectónicas curvas siendo un ejemplo elocuente de paramento iluminado (D). El sistema diseñado por SpacelabUK se denomina BIX Big Pixel, el cual convierte focos fluorescentes convencionales de 40 centímetros de diámetro en pixels visibles a través de la forma sinuosa del edificio, realizada con superficies curvas de paneles acrílicos semitransparentes de color azul. Bajo dicha piel, el sencillo sistema de 930 lámparas fluorescentes de 40 watios dispuestas en cuadrícula reproduce gráficos de ultra-baja resolución, apenas un 0,2\% de la habitual en una pantalla de TV, orientadas hacia el río para ser vistas a gran distancia. Poco tiempo antes, en 2001, ya se había realizado la exitosa instalación Blinkenlights diseñada por Chaos Computer Club, que convirtió la fachada racionalista de la Haus des Lehrers (1961-64) de Hermann Henselmann en un tablero interactivo compuesto por 144 lámparas distribuidas en 8 plantas, produciendo una trama de $8 \times 18$ pixels visible desde Alexanderplatz. Gracias al software de código abierto, Blinkenlights se repitió en el Ayuntamiento de Toronto en 2008, poniendo de relieve para futuros proyectos que el éxito de la instalación mediática residía en la participación del público gracias al proceso de interacción colectiva, y no tanto por lo sofisticado de los medios técnicos empleados (Figura 8).
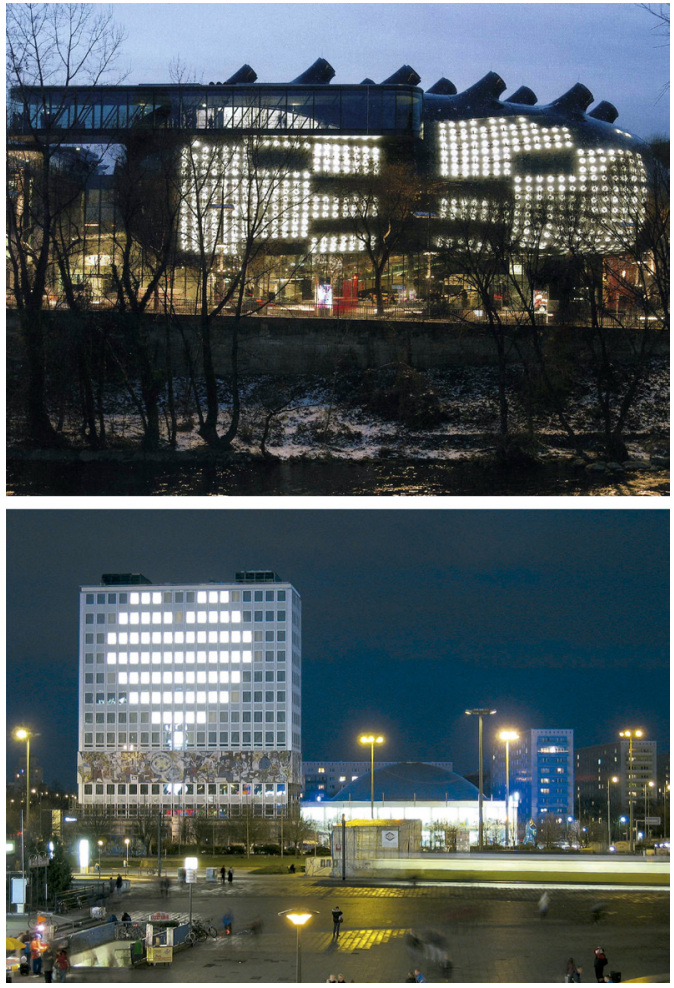

Figura 8: SpacelabUK: Peter Cook y Colin Fournier Kunsthaus Graz. Graz, 2003 (arriba). Hermann Henselmann; CCC (Chaos Computer Club). Blinkenlights Haus des Lehrers, Berlín 2001 (abajo)

Fuentes: Haeusler, M. H. (2009). Media facades: history, technology, content. Ludwigsburg: Avedition. / http:// blinkenlights.net/. Imagen de dominio público

Siguiendo antecedentes, la tecnología LED ha producido arquitecturas mediáticas de tipo pantalla (F) firmadas por nombres propios de este campo como UNStudio - Ben van Berkel, Bjarke Ingles Group (BIG) u Ove Arup \& Partners (Figura 9). Este último equipo de ingeniería desarrolla y construye en 2008 junto a Simone Giostra \& Partners el GreenPix-Zero Energy Wall en Beijing, el primer paramento mediático de consumo energético cero, que combina la tecnología fotovoltaica para adquirir energía de día y alimentar la iluminación LED de noche. Sin duda, el reto que supone la sostenibilidad de este tipo de sistemas es una de las claves en su futuro desarrollo. En este caso, el diseño permite emitir videoarte de baja resolución funcionando como un organismo cíclico sostenible, un ejemplo de responsabilidad medioambiental singular en este sentido en comparación con el resto analizado. El GreenPix-Zero Energy Wall condensa en sí toda la carga iconográfica de lo que se ha denominado la ciudad de los medios (McQuire, 2008).

\section{Nuevos paradigmas}

La función comunicativa de la arquitectura, más allá de la tectónica, ha sido una constante a lo largo de la historia. Las narrativas iconográficas habitualmente grabadas en piedra, madera o vidrio coloreado han sido hoy sustituidas por narrativas digitales sobre soportes tecnológicos 

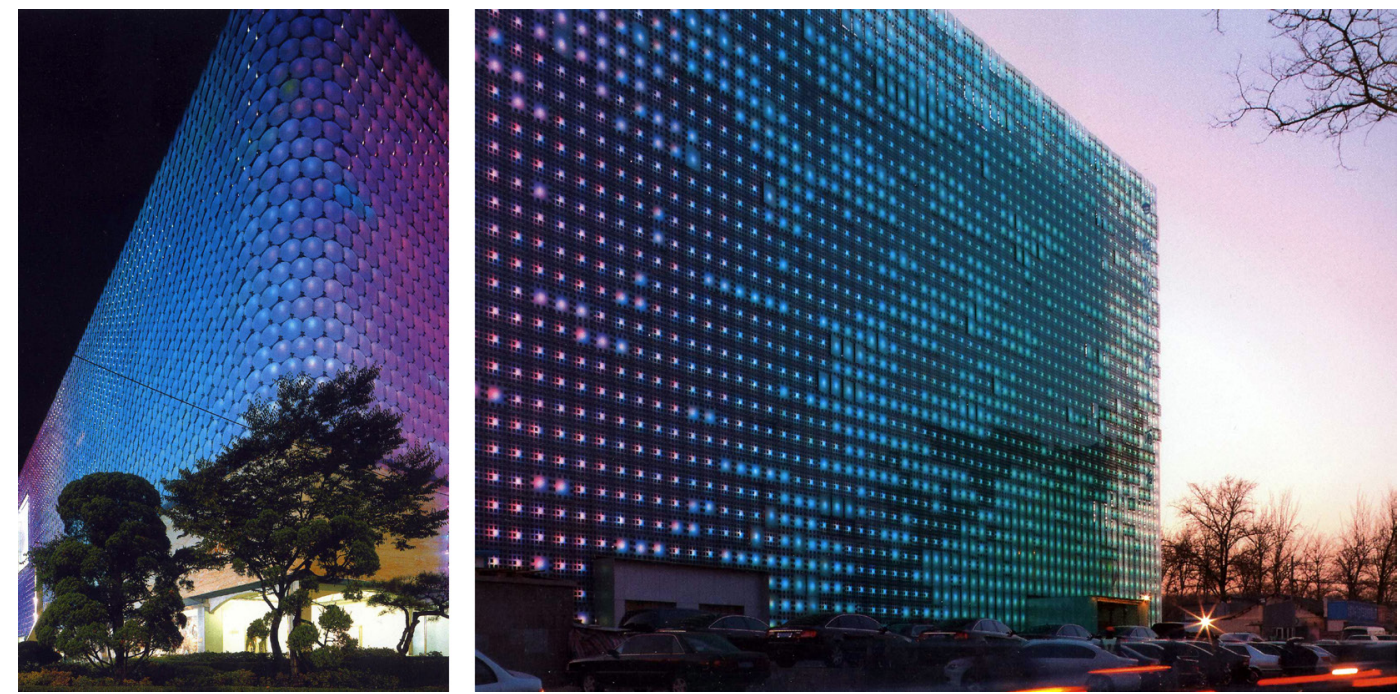

Figura 9: UNStudio - Ben van Berkel. Grandes Almacenes. Seúl, 2004 (izda). Simone Giostra \& Partners; Ove Arup \& Partners. GreenPix-Zero Energy Wall. Beijing, 2008 (dcha)

Fuentes: Haeusler, M. H. (2009). Media facades: history, technology, content. Ludwigsburg: Avedition

que amplían el potencial de la arquitectura de manera exponencial. No obstante, las claves de esta función comunicativa no residen en la tecnología del medio empleado sino en la capacidad de percepción e interacción del usuario (Hansen, 2004). Es decir, cabe considerar la obra construida como un todo integral en el que coexiste la capa de información proyectada en sus paramentos, independientemente de que esta se encuentre labrada en piedra o iluminada digitalmente.

En ese sentido, Robert Venturi abunda en el concepto de "superficie comunicativa" aplicada a la arquitectura en la era de la información (Venturi, 1966; Venturi et al., 1972; Venturi, 1998). Venturi analiza la cultura publicitaria, con el paradigma de Las Vegas como referente, y concluye que las pantallas electrónicas no son un simple aditamento del edificio, sino que pueden ser un pilar en la concepción del proyecto arquitectónico contemporáneo (Venturi, 1998). De forma similar, Paul Virilio pone el foco en el papel clave que los medios digitales y la cultura de la pantalla comercial tienen en la experiencia arquitectónica de la ciudad. Virilio (1991) habla de la "arquitectura de la comunicación" (p. 80) argumentando que nuestra percepción del espacio físico y del tiempo está íntimamente ligada a la capa de información que proporcionan los dispositivos multimedia presentes en calles y ciudades, a los que hoy día sumamos los dispositivos móviles que portamos con nosotros. Virilio entiende las pantallas como ventanas abiertas a otros espacios y tiempos, próximos o lejanos. De acuerdo con sus argumentos, todo ello fragmenta nuestra percepción del espacio construido y contribuye a la aparente desmaterialización de la arquitectura (Virilio, 1991).

Paradójicamente, los argumentos de Venturi y Virilio analizados a la luz de experiencias urbanas icónicas como Shibuya en Tokio, Yonge-Dundas Square en Toronto; Picadilly Circus en Londres o Times Square en Nueva York, esta última "quizás, la quintaesencia de un entorno urbano digital" según Anthony Townsend (2004, p. 102), pueden resultar cuando menos malinterpretados, por elevar a la categoría de referente dichas ceremonias de la confusión y el exceso de sistemas mediáticos superpuestos (García-Carrizo, 2016; Gorostiza, 2018). De hecho, es así. Ben van Berkel (2012) lo denomina "El efecto Times Square" (p. 8), en el que la arquitectura asume un papel secundario, de simple soporte, negando su presencia en favor de intereses publicitarios y anuncios que la hacen desaparecer. La fenomenología de tales enclaves urbanos, próxima al espectáculo de masas, desata un potencial que, a nuestro juicio, la arquitectura puede aprovechar solo en la medida en que las TIC se pongan al servicio de un diseño arquitectónico racional y sostenible (Haeusler, 2009).

En ese sentido, autores como Luigi Puglisi, Anthony Townsend o M. Hank Haeusler, han pretendido arrojar luz sobre nuevos paradigmas que nos permiten identificar cuándo el entorno arquitectónico responde positivamente al calificativo de mediático.

Según Luigi Puglisi (1999) la arquitectura mediática consta de "inmaterialidad; sensorialidad y multimedia" (pp. 7-8). La "inmaterialidad" se cifra en la idea de sistema, detectable por ejemplo en la obra de Archigram. Este principio relega a un segundo plano los problemas compositivos, tradicionalmente asociados a fachadas y plantas, en favor de subrayar las conexiones y relaciones entre espacios, los flujos entre funciones y actividades sociales, la mayoría de ellas de carácter inmaterial. La "sensorialidad" alude a la analogía arquitectónica del sistema nervioso, basado en impulsos electrónicos. Y finalmente, el atributo "multimedia" representa la capacidad de un edificio para acoger mensajes diversos a través de diversos media, integrándolos en un tejido construido único, arquitectónicamente lógico, que irradia luz, color y sonido, al tiempo que comunica información (Puglisi, 1999).

Por su parte, Anthony Townsend (2004) establece cuatro paradigmas técnicos denominados: "visualización; comunicaciones; posicionamiento y documentación" ( $p$. 
100). Tecnologías como las pantallas LED han aumentado la capacidad de "visualización" y el número de proyectos de este tipo, sobre todo en el entorno urbano. Las "comunicaciones" mediante redes inalámbricas están cambiando la manera en que el usuario se relaciona con el entorno construido. El "posicionamiento", unido a los dispositivos móviles, puede incluso modificar los flujos de movimiento dentro de un edificio, lo que significa que más allá de que el usuario perciba el entorno mediáti$c 0$, es la arquitectura la que advierte la localización del usuario pudiendo, hipotéticamente, reaccionar a ella. Y en última instancia, la fusión de la tecnología de bases de datos con la cartografía informatizada ha dado lugar a sistemas de información geográfica (GIS) cada vez más sofisticados, que incrementan nuestra capacidad de "documentación" de los entornos urbanos (Haeusler, 2009). En palabras del propio Anthony Townsend (2004) estos cuatro paradigmas: "ofrecen pruebas convincentes de las sinergias que son posibles cuando se combinan dos o más de estas tecnologías para proporcionar una nueva flexibilidad y capacidad a las interacciones entre el hombre y el entorno construido" (p. 102).

Finalmente, M. Hank Haeusler (2009) habla del paradigma del contenido con relación al tiempo: "pregrabado; en directo o interactivo" (p. 225), cuestión que sin duda condiciona directamente la experiencia del usuario. El contenido "pregrabado" es anterior al momento de su emisión y puede ser repetido tantas veces como se desee. El contenido "en directo" se utiliza habitualmente en eventos masivos, deportivos, conciertos, etc... En este caso los paramentos mediáticos suelen ser efímeros porque la concentración de público objetivo también lo es. En última instancia, el contenido "interactivo" es el más complejo de diseñar, pero también el más sugerente en términos fenomenológicos y arquitectónicos. Según Arjen Mulder "podemos Ilamar a cualquier sistema 'interactivo' si es lo suficientemente flexible como para adaptarse al uso que se hace de él y si, a la inversa, este provoca cambios en sus usuarios a partir de los cambios que estos provocan en el sistema. En otras palabras: cuando los sistemas están vinculados entre sí y se modifican mutuamente a través de este vínculo, hablamos de interactividad" (Mulder, 2004, p. 332). Como diría Sheizaf Rafaeli, la interactividad lo es en "la medida en que la comunicación se refleja en sí misma, se alimenta del pasado y responde a él” (Newhagen y Sheizaf, 1996, pp. 4-13).

En términos arquitectónicos, los proyectos clasificados en este estudio ostentan dichos paradigmas en diferentes grados de cumplimiento, si bien todos ellos combinados nos presentan un modelo de arquitectura mediática ideal, de ida y vuelta, que de manera similar a cómo se produce el conocimiento humano, sugiere un espacio creado con el potencial de cambiar y aprenderse desde la interacción entre el ser humano y el artificio.

\section{Conclusiones}

A la luz de lo expuesto, resulta evidente que los atributos performativos, dinámicos y múltiples que caracterizan la arquitectura mediática no son una apuesta exclusiva del mundo contemporáneo. Autores como Herbert Bayer Josef Svoboda y los Eames diseñaron entornos inundados de imágenes y pantallas, produciendo experiencias de vanguardia como la disolución de los límites en términos de percepción, anticipando la idea de paisaje arquitectónico audiovisual. Por otro lado, de los estudios de Robert Venturi y Paul Virilio se desprende que el desarrollo de la publicidad a escala urbana y los paramentos convertidos en pantallas desempeñan un papel relevante en dicho paisaje arquitectónico audiovisual, en la construcción de la ciudad contemporánea entendida, cada vez más, como una ciudad performativa.

La notable evolución de las tecnologías de la información y la comunicación (TIC) en las últimas décadas ha nutrido esta tendencia arquitectónica; mediascapes, realidades aumentadas, paisajes de datos, ciberespacio, virtualización, por citar solo algunas de sus derivadas (Stojšić, 2017). Los avances que el diseño arquitectónico está incorporando a través de su positiva hibridación activan una nueva fenomenología del espacio construido, especialmente urbano, transformando los límites, distorsionando la percepción del tiempo y estableciendo un diálogo entre los espacios real y virtual.

No obstante, del análisis clasificatorio del presente estudio se desprenden dos retos de futuro para la arquitectura mediática. El primero pasa por la sostenibilidad de este tipo de sistemas. El porcentaje de ejemplos analizados hasta 2016 que aborda la sostenibilidad energética en su diseño de manera explícita es escaso, si bien este resulta un factor hoy día ineludible. A nuestro juicio, las arquitecturas mediáticas tienen el potencial para erigirse como transformadores sociales, económicos y medioambientales de las ciudades. De forma pionera Ken Yeang ya proponía en Tropical Urban Regionalism (1987) una ecología electrónica consecuencia de este tipo de proyectos.

El segundo reto es de índole social. Como señala Angelique Trachana (2021): "La tecnología digital, como toda innovación técnica, se enfrenta a la necesidad antropológica de ligarse a todos los aspectos estéticos y expresivos, y es productora de símbolos y significados" (p. 182). Es decir, solo en la medida en que la arquitectura mediática sea capaz de integrar la complejidad de las experiencias individuales y colectivas, mediando entre la tecnología, el edificio, el emplazamiento, el contenido audiovisual y la responsabilidad medioambiental, esta tendrá sentido perdurable como referente para la vida cotidiana.

La arquitectura mediática subraya el infinito potencial derivado de la proliferación masiva de las TIC, un ecosistema de disciplinas que pone el foco en la dimensión de la imagen y la información como materia y material conceptual de la arquitectura contemporánea.

Cómo citar este artículo/How to cite this article: Rincón-Borrego, I., Alonso-García, E., Pérez-Barreiro, S. y Villalobos-Alonso, D. (2022). Arquitecturas pantalla en la era de la información. Notas sobre paramentos mediáticos y nuevos paradigmas. Estoa. Revista de la Facultad de Arquitectura y Urbanismo de la Universidad de Cuenca, 11 (21), 127-140. https://doi.org/10.18537/est.v011.n021.a11 


\section{Referencias bibliográficas}

AA.VV. (2006). ag4 mediatecture company. Media Facades. Ed. daab.

Bablet, D. (1970). Josef Svoboda. La Cité.

Bayer, H. y Gropius, W. (1930). Section Allemande Catalogue. Verlag Hermann, Reckendorf.

Bayer, H. (1939). Fundamentals of Exhibition Design. PM Production Manager, 6(2), 17-25.

Bayer, H. (1967). Herbert Bayer: Painter, Designer, Architect. Reinhold.

Brüning, U. (1982). Zur Typografie Herbert Bayers. En M. Droste (Ed.), Herbert Bayer. Das künstlerische Werk 1918- 1938 (pp. 118-137). Bauhaus-Archiv y Gebr. Mann.

Brüning, U. (Ed.). (1995). Das A und O des Bauhauses. Ed. Leipzig.

Burian, J. (1971). The Scenography of Josef Svoboda Wesleyan University Press.

Colomina, B. (2001). Enclosed by Images: The Eameses' Multimedia Architecture. Grey Room, (2), 7-29. http:// www.jstor.org/stable/1262540

Eisenmann, P. (1997). Iglesia para el año 2000. La iglesia en la era de la información. El Croquis, (83), 156.

García-Carrizo, J. (2016). Ciudad y pantallas digitales publicitarias: Motivos, funciones y efectos de su implantación. En M. A. Chaves (Ed.), Ciudad y comunicación. Universidad Complutense de Madrid.

Gorostiza, J. (2018). Fachadas y pantallas. Lo real transformado en ficción. Collectivus, Revista de Ciencias Sociales, 5(1), 40-62. https://doi.org/10.15648/Coll.1.2018.4

Haeusler, M. H. (2009). Media facades: history, technology, content. Avedition.

Haeusler, M. H., Tomitsch, M. y Tscherteu, G. (2012). New Media Facades. A Global Survey. Avedition.

Hespanhol, L., Haeusler, M. H., Tomitsch, M. y Tscherteu, G. (2017). Media Architecture Compendium. Digital Placemaking. Avedition.

Hansen, M. (2004). New Philosophy for New Media. The MIT Press.

Ito, T. y Maffei, A. (2001). Toyo Ito: le opere, i progetti, gli scritti. Electa.

Ito, T., Torres Nadal, J. y Abalos, I. (2000). Escritos. Colegio Oficial de Aparejadores y Arquitectos Técnicos de Murcia.

Jaeggi, A. (2007). Werkbund-Ausstellung Paris 1930. Leben im Hochhaus. Bauhaus-Archiv.
Lotz, W. (1930). Ausstellung des Deutschen Werkbundes in Paris. Die Form, 5(11/12), 281-296.

Lupton, E. (2020). Herbert Bayer. Inspiration and Process in Design. Princeton Architectural Press.

Marinelli, G. (1978). I/ Centro Beaubourg a Parigi: "machina" e segno architettonico. Dedalo Libri.

McQuire, S. (2008). The Media City. Media, architecture and Public Space. SAGE Publications.

Miller, W. (2017). Points of View: Herbert Bayer's Exhibition Catalogue for the 1930 Section Allemande. Architectural Histories, 5(1), 1-22. https://doi.org/10.5334/ ah.221

Mulder, A. (2004). The Object of Interactivity. En L. Spuybroek (Ed.), NOX: machine architecture. Thames \& Hudson.

Neuhart, J., Neuhart, M. y Eames, Ch. (1989). Eames Design: The Work of the Office of Charles and Ray Eames. Harry N. Abrams.

Newhagen, J. y Sheizaf, R. (1996). Why communication researchers should study the internet: A dialogue. Journal of communication, 4(1), 4-13. https://doi.org/10.1111/j.1083-6101.1996.tb00172.x

Nieto, M. (2016). Más allá de la pantalla. Espacios dinámicos, múltiples y transformables. En A. Costa y R. Capucho (Coord.). Avanca Cinema. International Conference 2016. (pp. 1099-1107). Cineclube de Avanca.

Ostroff, D. (2015). An Eames anthology: Articles, film scrpits, interviews, letters, notes, speeches by Charles and Ray Eames. Yale University Press.

Perrella, S. (2001). Hypersurface theory: Architecture $><$ Culture. En G. Cristina (Ed.), Architecture and Science. (pp. 138-148). Chichester.

Piano, R., Rogers, R. y Picon, A. (1987). Du Plateau Beaubourg au Centre Georges Pompidou. Centre Georges Pompidou.

Puglisi, L. P. (1999). Hyperarchitecture Spaces in the Elec tronic Age. Birkhäuser.

Roulet, S. y Soulié, S. (1991). Toyo Ito: I'architecture de l'éphémère. Moniteur.

Stojšić, M. (2017). Media Facades: Architecture and/as a Medium in Urban Context. AM Journal of Art and Media Studies, (12), 135-148. http://dx.doi.org/10.25038/ am.v0i12.173

Townsend, A. (2004). Digitally mediated urban space: New lessons for design. PRAXIS: Journal of Writing + Building, 6, 102 
Trachana, A. (2021). Envolventes performativas y “la ciudad escena". Bitácora Urbano Territorial, 31(2), 173-187. https://doi.org/10.15446/bitacora.v31n2.85992

Ursini, G. (Ed.) (2009). Josef Svoboda. Escenógrafo. El mundo en un espejo. Litograf.

Venturi, R. (1998). Iconography and Electronics upon a Generic Architecture: A View from the Drafting Room. The MIT Press.

Venturi, R. (1966). Complexity and Contradiction in Architecture. Museum of Modern Art.

Venturi, R., Scott Brown, D. y Izenour, S. (1972). Learning from Las Vegas. The MIT Press.

Vermeir, K. (2005). The magic of the magic lantern (1660-1700): on analogical demonstration and the visualization of the invisible. The British Journal for the History of Science, 38(2), 127-159. http://dx.doi.org/10.1017/ S0007087405006709

Virilio, P. (1991). Lost Dimension. Semiotext(e).

Yeang, K. (1987). Tropical Urban Regionalism. Concept Media. 